\title{
ERRATUM
}

\author{
Demetris Pentaras • Isaac Elishakoff
}

\section{Erratum to: Free vibration of triple-walled carbon nanotubes}

Published online: 11 February 2012

(C) Springer-Verlag 2012

\section{Erratum to: Acta Mech 221, 239-249 (2011) \\ DOI 10.1007/s00707-011-0496-9}

The original publication of the article includes an error in the representation of " $\mathrm{d}$ " in the second paragraph under Sect. 3. The incorrect sentence " $d$ is the mean diameter of the outermost tube" should actually read " $\mathrm{d}$ is the mean diameter of the middle tube".

Acknowledgements We appreciate helpful comments by Professor S. Rajasekaran of the Infrastructure Engineering, PSG College of Technology, Coimbatore, Tamilnadu, India.

The online version of the original article can be found under doi:10.1007/s00707-011-0496-9.

D. Pentaras $(\bowtie)$

Department of Mechanical Engineering and Materials Science and Engineering,

Cyprus University of Technology, 3041 Limassol, Cyprus

E-mail: demetris.pentaras@cut.ac.cy

Tel.: +357-25002275

D. Pentaras - I. Elishakoff

Department of Ocean and Mechanical Engineering, Florida Atlantic University, Boca Raton, FL 33431-0991, USA

E-mail: elishako@fau.edu 